\title{
PENINGKATAN AKTIVITAS GERAK LOKOMOTOR, NONLOKOMOTOR DAN MANIPULATIF MENGGUNAKAN MODEL PERMAINAN PADA SISWA SEKOLAH DASAR
}

\author{
Arif Hidayat ${ }^{1 *}$ \\ ${ }^{1}$ Universitas Bina Darma \\ email : arif.hidayat@binadarma.ac.id
}

\begin{abstract}
Abstrak
Masalah penelitian ini adalah aktivitas, kemampuan dan keterampilan teknik dasar gerak lokomotor, nonlokomotor dan manipulatif siswa SD Negeri 3 Tanjung Agung Kabupaten Muara Enim masih rendah. Penelitian Tindakan Kelas ini bertujuan untuk meningkatkan Aktivitas, kemampuan dan keterampilan teknik dasar gerak lokomotor, nonlokomotor dan manipulatif siswa SD Negeri 3 Tanjung Agung Kabupaten Muara Enim. Subjek penelitian adalah siswa kelas III tahun ajaran 2016/2017 di Sekolah Dasar Negeri 3 Kecamatan Tanjung Agung Kabupaten Muara Enim yang berjumlah 30 orang. Teknik pengumpulan data dengan melakukan observasi, tes, dan dokumentasi. Teknik analisis data adalah analisis kualitatif. Hasil penelitian menunjukkan bahwa Keaktifan siswa pada gerak lokomotorik pra siklus adalah $10 \%$ (sedang), pada gerak non lokomotorik $29 \%$ (sedang), dan pada gerak manipulatif $3,3 \%$ (sedang). Keaktifan siswa pada gerak lokomotorik siklus 1 adalah 56,6\% (sedang), pada gerak non lokomotorik $76 \%$ (sedang), dan pada gerak manipulatif $60 \%$ (sedang). Keaktifan siswa pada gerak lokomotorik pra siklus adalah $80 \%$ (tinggi), pada gerak non lokomotorik $83 \%$ (tinggi), dan pada gerak manipulatif $86,6 \%$ (tinggi). Melalui penerapan metode bermain Kera Panjat dalam Penelitian Tindakan kelas ini diketahui bahwa terjadi peningkatan keaktifan siswa pada gerak lokomotorik sebesar $70 \%$, gerak non lokomotorik $54 \%$, dan gerak manipulatif $83,3 \%$.
\end{abstract}

Kata kunci: Aktivitas Gerak, Lokomotor, Nonlokomotor, Manipulatif \& Model Permainan

\begin{abstract}
This research Issue was activities, capabilities and skills of the basic techniques of motion nonlokomotor, locomotor and manipulative elementary school students number 3 Tanjung Agung, Muara Enim Regency is still low. Class action research aims to improve the activities, capabilities and skills of the basic techniques of motion nonlokomotor, locomotor and manipulative elementary school students number 3 Tanjung Agung, Muara Enim Regency. The subject of research is the grade III in 2016/2017 teaching in primary schools of the country 3 Tanjung Agung, Muara Enim Regency that add up to 30 people. Data collection techniques by doing observation, tests, and documentation. Technique of data analysis is qualitative analysis. The results showed that students at the liveliness of motion lokomotorik pre cycle is 10\% (being), on a motion of non lokomotorik 29\% (medium), and on the motion of the manipulative $3.3 \%$ (medium). The liveliness of the students on the motion of the lokomotorik cycle 1 was $56.6 \%$ (being), on a motion of non lokomotorik $76 \%$ (medium), and on the motion of the manipulative 60\% (medium). The liveliness of the students in motion pre lokomotorik cycle is $80 \%$ (high), on a motion of non lokomotorik 83\% (high), and on the motion of the manipulative 86.6\% (high). Through the application of methods of playing Monkey Climb in this class Action Research Note that an increase in activity of students in motion lokomotorik of 70\%, 54\% non lokomotorik motion, and the motion of the manipulative $83.3 \%$.
\end{abstract}

Keywords: Motion activity, Non locomotor, Locomotor, Manipulative \& Model Game. 


\section{PENDAHULUAN}

Penjasorkes adalah suatu mata pelajaran yang dipelajari siswa di sekolah. Mata pelajaran ini meliputi materi tentang cabang-cabang olahraga, olahraga permainan, dan materi tentang kesehatan lingkungan serta kesehatan tubuh. Pembelajaran penjasorkes merupakan mata pelajaran yang tidak hanya mengajak siswa menguasai cabang olahraga tertentu tetapi juga membentuk karakter siswa dengan memiliki gaya hidup sehat. Pembelajaran Penjasorkes merupakan suatu proses melaksanakan kegiatan belajar mengajar pada bidang olahraga dan kesehatan, dilakukan oleh guru dan siswa. Guru merupakan orang yang melakukan tugas mengajar memberi materi pelajaran, membimbing, dan mengarahkan kegiatan siswa. Siswa merupakan pelaku belajar yang melaksanakan kegiatan belajar yang sudah dirancang oleh guru.

Perkembangan gerak dimasa anak-anak sangat menonjol,terutama pada kemampuan gerak lokomotor, nonlokomotor dan manipulatif. Penyempurnaan atau perbaikan gerak dasar terjadi pada masa anakanak. Menjelang masa remaja gerak yang makin kompleks bisa dikuasai dengan kemampuan memanfaatkan keterampilan gerak sesuai dengan kebutuhannya. Pada akhirnya masa awal dewasa berbagai organ tubuh mencapai puncak perkembangan fungsi, dan fisik mencapai puncak kematangannya.

Keberadaan metode sebagai alat menyampaikan materi penting dalam proses pembelajaran karena dengan metode yang tepat materi pembelajaran yang sudah siap diajarkan dapat diterima dengan mudah oleh siswa melalui kegiatan belajar yang aktif. Mulyasa (2010:25) mengatakan bahwa guru harus pandai memilih metode yang tepat digunakan dalam proses belajar siswa. Kenyataannya di lapangan tidak semua guru dapat memilih metode pembelajaran yang tepat dalam pembelajaran. Salah satu ruang lingkup pendidikan jasmani adalah pembentukan gerak, yang meliputi keinginan untuk bergerak, menghayati ruang waktu dan bentuk termasuk perasaan irama, mengenal kemungkinan gerak diri sendiri, memiliki keyakinan gerak dan perasaan sikap (kinestetik) dan memperkaya kemampuan gerak (Saputra, 2000). Kemampuan gerak dasar ada tiga jenis yaitu lokomotor, nonlokomotor dan manipulatif. Gerak lokomotor merupakan suatu gerakan yang ditandai dengan adanya perpindahan tempat, seperti jalan, lari, melompat dan mengguling. Gerakan ini biasanya membuat anak merasa senang melakukannya,karena pada umumnya anak-anak akan lebih tertarik untuk melakukan.

Dari hasil pengamatan awal peneliti di SD Negeri 3 Tanjung Agung Sabtu, 22 Oktober 2016 di kelas III pembelajaran Penjaskes tentang gerak dasar, saat pembelajaran menunjukkan bahwa siswa belum terampil dan menguasai untuk gerak lokomor, nonlokomotor, dan manipulatif, tentunya akan membatasi keterampilan dan kemampuan gerak dasar siswa yang akan berpengaruh pada pencapaian hasil pembelajaran. Salah satu penyebabnya adalah model pembelajaran yang tidak sesuai, sehingga tujuan pengajaran yang telah dirumuskan oleh pendidik belum mencapai hasil yang maksimal.

Gerak lokomotor dapat diartikan sebagai gerak memindahkan tubuh dari satu tempat ke tempat lain (Yudanto, 2011). Bentuk gerak lokomotor diantaranya berjalan, berlari, brjingkat, melompat dan meloncat, berderap, merayap dan memanjat. Definisi gerak lokomotor juga dijelaskan oleh Mahendra (2007: 32) menyatakan bahwa gerak lokomotor adalah gerak memindahkan tubuh dari satu tempat ke tempat yang lain, baik secara horisontal maupun secara vertikal. Gerakan tersebut diantaranya jalan, lari, lompat, loncat, jingkat, menderap, memanjat dan lain-lain.

Gerak nonlokomotor adalah gerakan yang dilakukan di tempat. Tanpa ada ruang gerak yang memakai kemampuan nonlokomotor terdiri dari menekuk dan meregang, mendorong dan menarik, mengangkat dan menurunkan, melipat dan memutar, mengocok, melingkar, melambungkan dan lain-lain (Saputra, 2000). Contoh gerak nonlokomotor adalah : mengulur, menekuk, mengayun, bergoyang, berbelok, berputar, meliuk, mendorong, mengangkat dan mendarat (Sukintaka, 1992). 
Gerak manipulatif adalah gerak yang dikembangkan ketika anak tengah menguasai bermacam objek. Kemampuan manipulatif lebih banyak melibatkan tangan dan kaki, tetapi bagian lain dari tubuh kita juga dapat digunakan. Bentuk-bentuk gerak manipulatif terdiri dari gerakan mendorong (melempar, memukul, menendang), gerakan menerima (menangkap) dan gerakan memantul-mantulkan bola atau menggiring bola (Saputra , 2000). Bermain merupakan suatu sarana penting bagi perkembangan sosial, emosional, dan kognitif anak juga merefleksikan perkembangannya, memberi kesempatan pada anak untuk memahami lingkungan, berinteraksi dengan yang lain dengan cara-cara sosial, mengekspresikan dan mengontrol emosi, serta mengembangkan kapabilitas anak (Ali dkk, 2009:105).

\section{METODE}

\section{Jenis Penelitian}

Penelitian adalah cara yang digunakan oleh peneliti dalam mengumpulkan data dari penelitian itu sendiri. Sehubungan dengan masalah yang diteliti. Jenis penelitian yang dilakukan adalah Penelitian Tindakan Kelas (PTK). Arikunto (2010:3) mengemukakan penelitian Tindakan Kelas merupakan suatu pencermatan terhadap kegiatan belajar berupa sebuah tindakan, yang sengaja dimunculkan dan terjadi dalam sebuah kelas secara bersama. Tindakan diberikan oleh guru atau dengan arahan dari guru yang dilakukan oleh siswa

\section{Desain Model Penelitian}

Adapun model tahapan-tahapan Penelitian Tindakan Kelas yaitu:

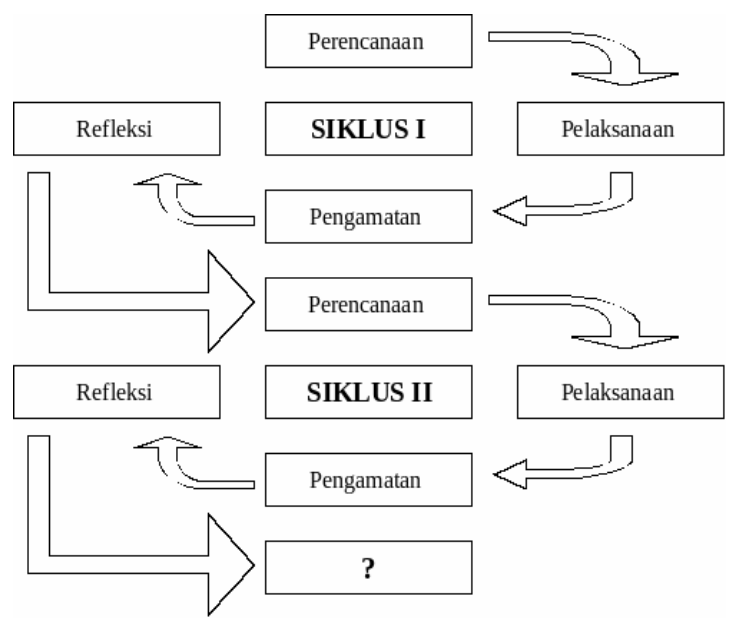

Gambar 2.1 Desain Penelitian

Khusus untuk penelitian tindakan kelas akhir-akhir ini mendapat prioritas dikalangan dunia pendidikan, karena kelas merupakan unit terkecil dalam suatu sistem pembelajaran, sehingga semua guru perlu mendalami dan mengkritis apa sebenarnya dilakukan oleh siswa maupun guru, dan apa yang sebenarnya terjadi. Dengan demikian guru akan dapat menentukan sendiri strategi guna meningkatkan efektifitas dan efisiensi pembelajaran dikelasnya secara kontekstual.

\section{Subyek Penelitian}

Subyek penelitian ini adalah adalah siswa kelas III SD Negeri II Tanjung Agung Kabupaten Muara Enim berjumlah 30 orang, terdiri dari 12 siswa putra dan 18 siswa putri. Obyek penelitian adalah keaktifan siswa dalam gerak lokomotorik dan manipulatif pada pembelajaran penjasorkes melalui metode bermain. 
Tabel 3.1 Subjek Penelitian

\begin{tabular}{cccc}
\hline Kelas & Putra & Putri & Jumlah \\
\hline III & 12 & 18 & 30 \\
Jumlah & 12 & 18 & 30 \\
\hline
\end{tabular}

Sumber TU SD Negeri 3 Tanjung Agung

Teknik Pengumpulan Data

Observasi

"Observasi adalah Pengumpulan data yang dilakukan dengan cara mengamati dan mencatat secara sistematik gejala-gejala yang diselidiki (Achmadi dan Narkubo, 2008:70)". Observasi digunakan untuk memperoleh data tentang aktivitas siswa selama pembelajaran berlangsung.

Tes

Teknik pengumpulan data yang digunakan dalam penelitian ini adalah teknik tes. "Teknik tes merupakan alat ukur yang sering ditemui dibidang penelitian pendidikan, psikologi maupun sosiologi" (Sukardi, 2003:138). Dari pendapat tersebut dapat disimpulkan bahwa teknik tes adalah teknik yang dilakukan untuk mengetahui sejauh mana kemampuan siswa dalam melakukan tes.

\section{Teknik Analisis Data}

Sesuai dengan jenis penelitian, yaitu Penelitian Tindakan Kelas (PTK), maka analisis yang tepat adalah menggunakan deskriptif kuantitatif, melalui persentase (\%). Untuk melihat persentase ketuntasan belajar siswa digunakan rumus sebagai berikut:

$$
\mathrm{t}=\frac{m d}{\sqrt{\frac{\sum d 2}{N(N-1)}}}
$$

$$
\begin{array}{ll}
\mathrm{T} & \text { : nilai perbedaan } \\
\mathrm{N} & \text { : jumlah subjek } \\
\mathrm{Md} & \text { : rata-rata selisih antara X1 dan X2 } \\
\mathrm{d} & \text { : penyimpangan (selisih) antara X1 dan X2 }
\end{array}
$$

Analisis ini dilakukan pada saat tahapan refleksi. Hasil analisis ini digunakan sebagai bahan refleksi untuk melakukan perencanaan lanjut dalam siklus selanjutnya. Hasil analisis juga dijadikan sebagai bahan refleksi dalam memperbaiki rancangan pembelajaran atau bahkan mungkin sebagai bahan pertimbangan dalam penentuan model pembelajaran yang tepat.

Tabel 1. Kriteria Tingkat Keberhasilan Siswa

\begin{tabular}{cc}
\hline Tingkat Keberhasilan & Kriteria \\
\hline$>80 \%$ & sangat tinggi \\
$60-79 \%$ & tinggi \\
$40-59 \%$ & sedang \\
$20-39 \%$ & rendah \\
$<20 \%$ & sangat rendah \\
\hline \multicolumn{2}{l}{ Sumber RPP Sekola Dasar }
\end{tabular}




\section{HASIL DAN PEMBAHASAN}

Penelitian ini bertujuan untuk mengetahui peningkatan keaktifan gerak lokomotor, nonlokomotor, dan manipulatif siswa dalam pembelajaran penjasorkes melalui metode bermain siswa kelas III Sekolah Dasar Negeri 3 Tanjung Agung. Untuk mencapai tujuan tersebut, dalam tindakan kelas ini peneliti menggunakan metode bermain sebagai perlakuan. Jenis permainan yang dipilih adalah Kera Panjat.

\section{Deskripsi Data Hasil Siklus 1 \\ Perencanaan}

Perencanaan merupakan program yang berisi tentang kegiatan yang akan dilaksanakan dalam Penelitian Tindakan Kelas. Untuk mendukung pelaksanaan tindakan direncanakan hal-hal sebagai berikut.

1) Refleksi awal, meliputi kegiatan: (1) menyiapkan kegiatan bermain yang harus dilakukan siswa per individu; (2) menyiapkan cara bermain sebagai stimulus bagi siswa; (3) menyiapkan sarana dan prasarana pendukung; (4) menyiapkan RPP; dan (5) menyiapkan administrasi berupa lembar observasi, dan absen.

2) Menetapkan dan merumuskan rancangan tindakan, pada tahap ini kegiatan yang dilakukan adalah: (1) menentukan tujuan pembelajaran; (2) menyusun kegiatan pembelajaran untuk meningkatkan keaktifan gerak lokomotor dan manipulatif menggunakan metode bermain.

\section{Pelaksanaan}

Pelaksanaan tindakan kelas penelitian ini dilakukan untuk meningkatkan keaktifan gerak lokomotor, nonlokomotorik dan manipulatif. Perlakuan yang diterapkan adalah bermain Kera Panjat. Pelaksanaan permainan dilakukan dengan tahapan pertama, merencanakan kegiatan meliputi menyusun rencana pembelajaran untuk tindakan, menyiapkan kegiatan pembelajaran, menyiapkan lembar observasi, dan mengkoordinasikan program kerja pelaksanaan tindakan dengan guru lain. Setelah rencana pembelajaran dibuat, selanjutnya dilakukan kegiatan permainan dengan langkah sebagai berikut.

a. Permainan dimulai jika anak "Jadi" memberi aba-aba

b. Setalah aba-aba, pemain lawan bergegas untuk naik ke tempat yang tinggi, berupa pagar, pohon, atau batu

c. Para pemain tidak boleh terlalu lama di tempat tinggi karena harus berpindah-pindah sehingga menuntut ketangkasan dan taktik yang jitu.

\section{Observasi dan Evaluasi}

Observasi dalam tindakan kelas ini dilakukan pada siswa. Hasil observasi diperoleh melalui pengamatan langsung yang dilakukan peneliti dan dibantu oleh observer pendamping/ teman sejawat. Kegiatan yang dilakukan dalam observasi adalah sebagai berikut.

a. Melakukan pengamatan terhadap kegiatan siswa dalam bermain, baik secara individu maupun kelompok

b. Siswa bermain.Menilai keaktifan gerak lokomotor, nonlokomotorik dan manipulatif siswa secara teliti dan memberikan nilai sesuai dengan hasil yang diperoleh siswa

Penilaian keaktifan siswa dilakukan menggunakan lembar observasi. Setiap indikator yang diamati, yang tampak dari siswa diberi tanda ceklish $(\sqrt{ })$ dan diberi skor 1 , sedangkan yang tidak tampak diberi tanda negatif (-) dan diberi skor nol. Nilai akhir dicari persentasenya dengan cara menjumlahkan total skor yang tampak dibagi skor maksimum dikali $100 \%$. Diketahui bahwa keaktifan siswa dalam gerak lokomotorik tertinggi adalah 25 detik dan terendah 11 detik. Rata-rata keaktifan siswa adalah 16,4 dengan kriteria Sedang. Jumlah siswa yang memperoleh hasil dengan kriteria Sedang berjumlah 17 orang $(56,6 \%)$, selebihnya rendah berjumlah 13 orang $(43,4 \%)$. Lebih jelasnya dapat dilihat pada diagram di bawah ini. 


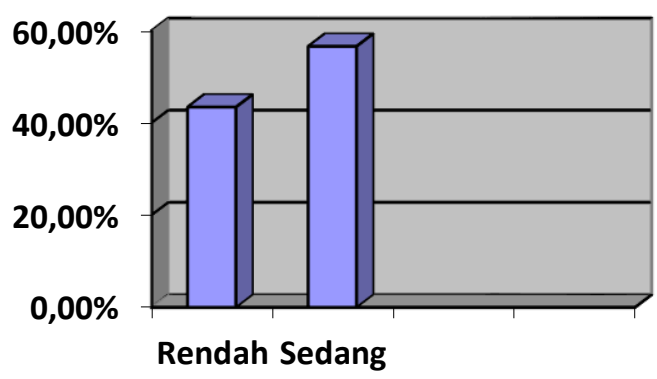

Gambar 3.1 Keaktifan Gerak Lokomotorik Siswa Siklus 1

keaktifan siswa dalam gerak nonlokomotorik tertinggi adalah 28 detik dan terendah 13 detik. Rata-rata keaktifan siswa adalah 18,5 dengan kriteria Sedang. Jumlah siswa yang memperoleh hasil dengan kriteria Sedang berjumlah 23 orang (76\%), selebihnya rendah berjumlah 7 orang (24\%). Lebih jelasnya dapat dilihat pada diagram di bawah ini.

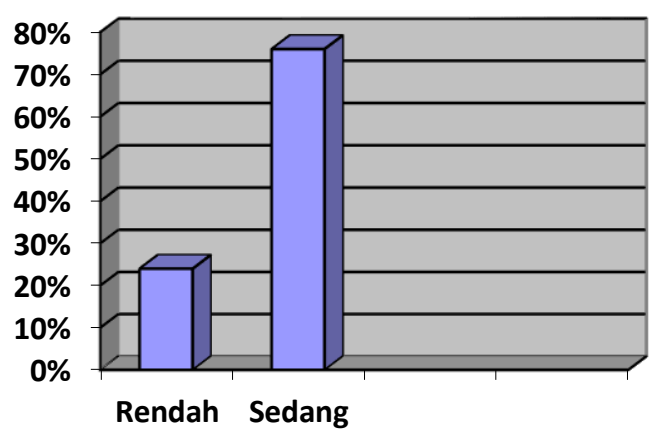

Gambar 3.2 Keaktifan Gerak Nonlokomotorik Siswa Siklus 1

keaktifan siswa dalam gerak manipulatif tertinggi adalah 13 kali dan terendah 7 kali. Rata-rata keaktifan siswa adalah 10,1 kali dengan kriteria sedang. Jumlah siswa yang memperoleh hasil dengan kriteria sedang berjumlah 18 orang (60\%), selebihnya rendah berjumlah 12 orang (40\%). Lebih jelasnya dapat dilihat pada diagram di bawah ini.

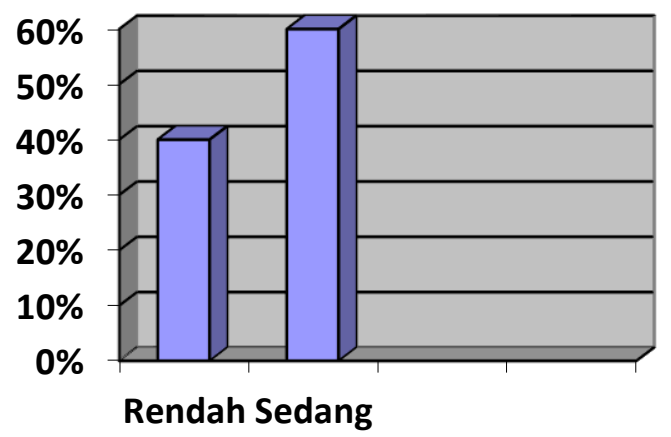

Gambar 3.3 Keaktifan Gerak Manipulatif Siswa Siklus 1

\section{Refleksi}

Setelah dilakukan observasi terhadap kegiatan siswa dalam pembelajaran tindakan kelas ini, maka dilakukan refleksi. Kriteria penilaian terhadap tindakan yang dilakukan dalam penelitian ini dapat diuraikan sebagai berikut. 
a. Hasil pengamatan telah menunjukkan bahwa pelaksanaan proses pembelajaran sesuai dengan rencana yang sudah ditentukan dan memberi hasil yang baik untuk semua komponen. Keaktifan gerak lokomotor, nonlokomotorik dan manipulatif siswa dikatakan baik jika telah mencapai nilai $\geq 75 \%$.

b. Siswa tidak mengalami kesulitan dalam bermain dan tidak pasif pada tiap akhir tindakan. Hal ini ditunjukkan apabila keaktifan siswa mencapai nilai $\geq 75 \%$.

Berdasarkan hasil tes terhadap keaktifan siswa dalam gerak lokomotorik, nonlokomotorik, dan gerak manipulatif pada siklus 1 bahwa keaktifan siswa belum mencapai kriteria keberhasilan dalam penelitian ini, kendatipun keaktifan siswa sudah meningkat dari pra siklus sampai pada siklus 1 . Hal ini terjadi karena terdapat kelemahan dalam pembelajaran dengan metode bermain, kesalahankesahatan tersebut adalah sebagai berikut.

a. Siswa belum mampu beradabtasi dengan kegiatan bermain Kera Panjat karena masih merasa permainan ini baru bagi siswa.

b. Siswa berebut peran ketika bermain

c. Waktu yang digunakan kurang efektif karena lebih banyak digunakan untuk penjelasan

d. Siswa belum mengerti aturan permainan.

Kelemahan tersebut menjadi indikator yang harus diperbaiki untuk kegiatan pada siklus 2.

\section{Deskripsi Data Hasil Siklus 2}

\section{Perencanaan}

Perencanaan merupakan program yang berisi tentang kegiatan yang dilaksanakan dalam Penelitian Tindakan Kelas. Untuk mendukung pelaksanaan tindakan siklus 2 direncanakan hal-hal sebagai berikut.

1. Refleksi awal, meliputi kegiatan: (1) menyiapkan kegiatan bermain yang harus dilakukan siswa per individu; (2) menyiapkan cara bermain sebagai stimulus bagi siswa; (3) menyiapkan sarana dan prasarana pendukung; (4) menyiapkan RPP; dan (5) menyiapkan administrasi berupa lembar observasi, dan absen.

2. Menetapkan dan merumuskan rancangan tindakan, pada tahap ini kegiatan yang dilakukan adalah: (1) menentukan tujuan pembelajaran; (2) menyusun kegiatan pembelajaran untuk meningkatkan keaktifan gerak lokomotor dan manipulatif menggunakan metode bermain.

\section{Pelaksanaan}

Pelaksanaan tindakan kelas siklus 2 dilakukan untuk meningkatkan keaktifan gerak lokomotor, nonlokomotorik dan manipulatif. Perlakuan yang diterapkan adalah bermain Kera Panjat. Pelaksanaan permainan dilakukan dengan tahapan sebagai berikut.

a. Permainan dimulai jika anak "Jadi" memberi aba-aba

b. Setalah aba-aba, pemain lawan bergegas untuk naik ke tempat yang tinggi, berupa pagar, pohon, atau batu

c. Para pemain tidak boleh terlalu lama di tempat tinggi karena harus berpindah-pindah sehingga menuntut ketangkasan dan taktik yang jitu.

\section{Observasi dan Evaluasi}

Observasi dalam tindakan kelas ini dilakukan pada siswa. Hasil observasi diperoleh melalui pengamatan langsung yang dilakukan peneliti dan dibantu oleh observer pendamping/ teman sejawat. Kegiatan yang dilakukan dalam observasi adalah sebagai berikut.

a. Melakukan pengamatan terhadap kegiatan siswa dalam bermain, baik secara individu maupun kelompok

b. Siswa bermain 
c. Menilai keaktifan gerak lokomotor, nonlokomotorik dan manipulatif siswa secara teliti dan memberikan nilai sesuai dengan hasil yang diperoleh siswa

Penilaian keaktifan siswa dilakukan menggunakan lembar observasi. Setiap indikator yang diamati, yang tampak dari siswa diberi tanda ceklish $(\sqrt{ })$ dan diberi skor 1 , sedangkan yang tidak tampak diberi tanda negatif (-) dan diberi skor nol. Nilai akhir dicari persentasenya dengan cara menjumlahkan total skor yang tampak dibagi skor maksimum dikali $100 \%$.

Diketahui bahwa keaktifan siswa dalam gerak lokomotorik tertinggi adalah 40 detik dan terendah 24 detik. Rata-rata keaktifan siswa adalah 36,1 dengan kriteria tinggi. Jumlah siswa yang memperoleh hasil dengan kriteria Sedang berjumlah 6 orang (20\%), selebihnya tinggi berjumlah 24 orang (80\%). Lebih jelasnya dapat dilihat pada diagram di bawah ini.

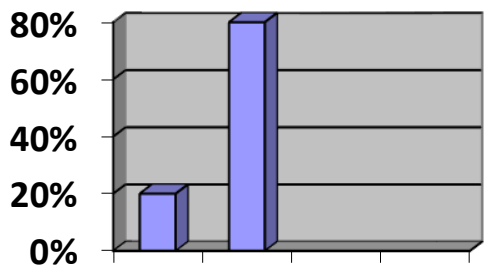

Sedanginggi

Gambar 3.4 Keaktifan Gerak Lokomotorik Siswa Siklus 2

Dapat diketahui bahwa keaktifan siswa dalam gerak nonlokomotorik tertinggi adalah 40 detik dan terendah 26 detik. Rata-rata keaktifan siswa adalah 36,6 dengan kriteria Tinggi. Jumlah siswa yang memperoleh hasil dengan kriteria Sedang berjumlah 5 orang (17\%), selebihnya tinggi berjumlah 25 orang $(83 \%)$. Lebih jelasnya dapat dilihat pada diagram di bawah ini.

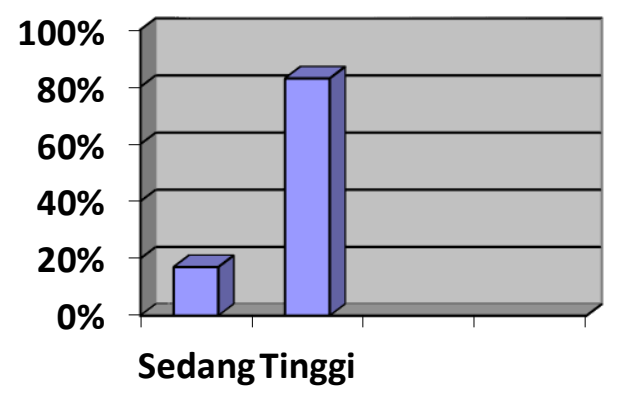

Gambar 3.5 Keaktifan Gerak Nonlokomotorik Siswa Siklus 2

Diketahui bahwa keaktifan siswa dalam gerak manipulatif tertinggi adalah 15 kali dan terendah 10 kali. Rata-rata keaktifan siswa adalah 14,2 kali dengan kriteria tinggi. Jumlah siswa yang memperoleh hasil dengan kriteria sedang berjumlah 4 orang $(13,4 \%)$, selebihnya rendah berjumlah 26 orang $(86,6 \%)$. Lebih jelasnya dapat dilihat pada diagram di bawah ini.

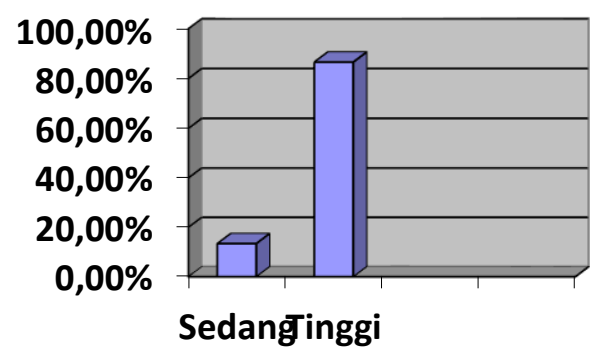

Gambar 3.6 Keaktifan Gerak Manipulatif Siswa Siklus 2 


\section{Refleksi}

Setelah dilakukan observasi terhadap kegiatan siswa dalam pembelajaran tindakan kelas ini, maka dilakukan refleksi. Pada siklus 2 ini tindakan yang dilakukan sudah mencapai hasil yang optimal karena sudah melebihi 75\% keberhasilan, baik pada gerak lokomotor, nonlokomotorik dan manipulatif. Oleh karena itu, tindakan kelas tidak dilanjutkan pada siklus berikutnya dan dinyatakan berhasil.

\section{KESIMPULAN}

Berdasarkan hasil penelitian dan pembahasan yang telah dipaparkan dapat disimpulkan bahwa:

1) Keaktifan siswa pada gerak lokomotorik pra siklus adalah $10 \%$ (sedang), pada gerak nonlokomotorik 29\% (sedang), dan pada gerak manipulatif 3,3\% (sedang).

2) Keaktifan siswa pada gerak lokomotorik siklus 1 adalah $56,6 \%$ (sedang), pada gerak nonlokomotorik $76 \%$ (sedang), dan pada gerak manipulatif $60 \%$ (sedang).

3) Keaktifan siswa pada gerak lokomotorik pra siklus adalah $80 \%$ (tinggi), pada gerak nonlokomotorik 83\% (tinggi), dan pada gerak manipulatif 86,6\% (tinggi).

4) Melalui penerapan metode bermain Kera Panjat dalam Penelitian Tindakan kelas ini diketahui bahwa terjadi peningkatan keaktifan siswa pada gerak lokomotorik sebesar $70 \%$, gerak nonlokomotorik 54\%, dan gerak manipulatif $83,3 \%$.

\section{DAFTAR PUSTAKA}

Arikunto, Suharsimi dkk. 2010. Penelitian Tindakan Kelas. Jakarta: Rineka Cipta.

Cholid Narbuko dan Abu Achmadi. 2008. Metodologi Penelitian. Jakarta: Bumi Aksara.

Mahendra, Agus. (2007). Teori Belajar Motorik. Bandung: FPOK Universitas Pendidikan Indonesia.

Mulyasa. 2008. Sertifikasi Guru dalam Proses Pembelajaran. Bandung: Alfabeta.

M. Yudha Saputra, 2007. Pembelajaran Atletik di Sekolah Dasar, Jakarta: Kencana.

Sukardi. 2003. Metodelogi Penelitian Pendidikan. Yogyakarta: Bumi Aksara.

Yudanto. 2011. Implementasi Pendekatan Taktik Dalam Pembelajaran Invasion Games di Sekolah Dasar. Fakultas Ilmu Keolahragaan Universitas Negeri Yogyakarta. 